\title{
BIOMARCADORES DEL METABOLISMO Y NUTRICIÓN DE HIERRO
}

\author{
Carmen Gloria Sermini 1,a, María José Acevedo 1,a, Miguel Arredondo 1,b
}

\begin{abstract}
RESUMEN
La anemia por deficiencia de hierro continúa siendo la deficiencia nutricional más abundante en el mundo, y son los lactantes, preescolares, mujeres en edad fértil y embarazadas los grupos de mayor susceptibilidad. Debido a esto es que se hace necesario el conocer los mecanismos de regulación de captación, transporte y absorción del metal a nivel celular, principalmente a nivel del enterocito y, una vez que el hierro entra a la circulación, conocer cuáles son los biomarcadores que permiten realizar un seguimiento del estatus del hierro corporal. En esta revisión mostramos, en primer lugar, cómo se regula la entrada de hierro a nivel de la célula del epitelio intestinal, mostrando las principales proteínas involucradas (transportadores de entrada y salida de hierro, oxido-reductasas, proteína de almacenamiento) $y$, para finalizar, hacemos un recuento de los principales biomarcadores del metabolismo de hierro una vez que este ha entrado y circula por el organismo.
\end{abstract}

Palabras clave: Hierro; Regulación Intracelular; Biomarcador; Valor de referencia; Inflamación. (Fuente: DeCS BIREME)

\section{BIOMARKERS OF METABOLISM AND IRON NUTRITION}

\begin{abstract}
Iron deficiency anemia is the most common nutritional deficiency worldwide, and the most susceptible groups are infants, preschoolers, women of childbearing age, and pregnant women. It is therefore essential to understand the mechanisms of regulation of iron uptake, transport, and absorption at the cellular level, particularly in enterocytes, and to identify blood biomarkers that allow the evaluation of iron status. This review describes how iron absorption is regulated by intestinal epithelial cells, the main proteins involved (iron transporters, oxidoreductases, storage proteins), and the main blood biomarkers of iron metabolism.
\end{abstract}

Key words: Iron; Intracellular Regulation; Biomarker; Reference value; Inflammation. (Source: MeSH NLM).

\section{INTRODUCCIÓN}

\section{METABOLISMO DEL HIERRO}

El hierro es un mineral esencial para la vida debido a que participa en múltiples funciones enzimáticas involucradas tanto en el transporte de oxígeno, metabolismo energético y síntesis de ADN, entre otras ${ }^{(1)}$. El contenido normal de hierro en el organismo es de aproximadamente $4 \mathrm{~g}$, de los cuales, $3 \mathrm{~g}$ forman parte de la hemoglobina, la mioglobina, las catalasas y otras enzimas respiratorias. El hierro almacenado corresponde a $0,5 \mathrm{~g} \mathrm{y}$, en su mayor parte, se encuentra depositado a nivel hepático ${ }^{(2)}$. A pesar de su gran importancia, el exceso de hierro se relaciona con morbilidad y mortalidad. Esto, debido a que puede producir daño celular por estrés oxidativo, mediante la generación de especies reactivas de oxigeno (ROS) a través de la reacción de Fenton, las cuales actúan sobre componentes biológicos como los lípidos, proteínas y $A D N{ }^{(3)}$, lo que determina que el metabolismo del hierro sea controlado por un potente sistema regulador.

\section{ABSORCIÓN DE Fe}

El hombre es capaz de reutilizar el hierro proveniente de la destrucción de los eritrocitos senescentes debido a la acción de los macrófagos del sistema retículo endotelial ${ }^{(4)}$. Además, del total de hierro que se moviliza diariamente, solo se pierde una pequeña proporción a través de las heces, orina, sudor y la descamación celular. Por lo que se requiere un pequeño aporte diario a través de la ingesta para reponer las pérdidas ${ }^{(5)}$.

\footnotetext{
Laboratorio de Micronutrientes, Instituto de Nutrición y Tecnología de los Alimentos, Universidad de Chile.

Nutricionista; ${ }^{\mathrm{b}} \mathrm{Msc}$; Phd

Recibido: 20/10/2017 Aprobado: 22/11/2017 En línea: 07/12/2017
} 
La dieta normal contiene aproximadamente $10-20 \mathrm{mg}$ de hierro, de lo cual, solo se absorben entre 1-2 mg al día, que puede variar en función de las necesidades tales como: la actividad de la médula ósea, el nivel de sus reservas, la concentración de hemoglobina, la concentración de oxígeno en sangre y las situaciones de inflamación a nivel sistémico ${ }^{(6,7)}$.

El hierro proveniente de la dieta puede estar disponible como hierro hemínico u orgánico, o como hierro no hemínico o inorgánico. El hierro hemínico se encuentra, principalmente, en las carnes (mioglobina) y sangre (hemoglobina), en cambio, las principales fuentes del hierro no hemínico son de origen vegetal, y en algunos alimentos de origen animal tales como la leche y el huevo, y se encuentra mayormente en su forma oxidada $\left(\mathrm{Fe}^{+3}\right)$ y unido a diversas macromoléculas ${ }^{(8)}$. A pesar de que el hierro no hemínico es la forma que más predomina en la dieta habitual (80-90\% del total del hierro), es el que presenta menor biodisponibilidad, puesto que su absorción puede ser interferida por otros factores dietarios tales como los fitatos, el calcio, o la mucina. Por otro lado, el hierro hemínico solo representa el $10-20 \%$ del hierro presente en la dieta, pero su absorción es más eficiente ${ }^{(9,10)}$. La absorción del hierro se da principalmente en el duodeno y su entrada al enterocito es mediada principalmente por el transportador de metales divalentes 1 (DMT1: para el hierro inorgánico) y por el transportador Heme Carrier Protein 1 (HCP1: para el hierro hemínico) ${ }^{(11)}$.

\section{ABSORCIÓN HIERRO NO HEMÍNICO}

La absorción del hierro no hemínico requiere de su solubilización y reducción del estado férrico $\left(\mathrm{Fe}^{+3}\right)$ a ferroso $\left(\mathrm{Fe}^{+2}\right)$ que comienza en el medio ácido gástrico, debido a que el hierro en estado férrico es muy poco absorbible ${ }^{(12)}$. Existen factores dietarios que también tienen la capacidad de reducir al hierro como el ácido ascórbico, la cisteína y la histidina. En el duodeno, la actividad de la enzima citocromo $B$ reductasa duodenal (DCytB) en el borde del cepillo, cumple con la función de reducir el hierro, debido a su actividad reductasa.

Luego de esta reducción, el hierro es ingresado al citoplasma mediante el transportador DMT1, el cual es capaz de transportar hierro y otros metales en su estado reducido, utilizando para ello el gradiente de potencial electroquímico de protones como fuente de energía. En el citoplasma, según las necesidades del nutriente, el hierro puede: 1) ser almacenado en la ferritina (proteína reservorio de hierro y que puede contener hasta 4500 átomos de hierro); 2) ser utilizado en los procesos metabólicos celulares, o 3) puede ser transportado a la sangre a través de la membrana basolateral, utilizando para ello al transportador ferroportina (también denominado IREG1). Junto a este transportador se encuentra la proteína hefestina (una óxido-reductasa) que reoxida el hierro a $\mathrm{Fe}^{+3}$ (esta actividad es realizada por la ceruloplasmina en el hepatocito). En este estado, es captado por la proteína plasmática transferrina que, finalmente, transporta el hierro a los tejidos periféricos ${ }^{(7,13)}$.

\section{ABSORCIÓN HIERRO HEMÍNICO}

El hierro hemínico, al encontrarse en la membrana apical del enterocito, es captado por el transportador HCP1 ${ }^{(14)}$. Luego, en el citoplasma, la enzima hem oxigenasa $(\mathrm{HO})$ degrada al grupo hem, liberando hierro, monóxido de carbono y biliverdina. El hierro liberado pasa a formar parte del pool de hierro lábil, al igual que el hierro no hemínico, y puede ser almacenado de igual manera en la ferritina o transportarse en la sangre a través de la ferroportina. La Figura 1, resume la absorción en el enterocito del hierro hemínico y no hemínico ${ }^{(5,7)}$.

\section{TRANSPORTE DE HIERRO EN LA CIRCULACIÓN}

La concentración de hierro en plasma en adultos normales es alrededor de $1,5 \mu \mathrm{g} / \mathrm{mL}$. La principal proteína trasportadora de Fe es la transferrina ( $\mathrm{Tf}$ ), que capta el hierro requerido desde el lumen intestinal y de los lugares de degradación de la hemoglobina (sistema monocito-macrófago) ${ }^{(15)}$. La Tf puede unir de manera reversible dos átomos de $\mathrm{Fe}^{+3}$, y este, puede ser internalizado por las células de los distintos tejidos mediante endocitosis a través del receptor para transferrina (RTf). La transferrina al unirse a su receptor que se encuentra en la superficie celular, forma el complejo RTfTf,-Fe que luego es endocitado. En el endosoma, $\mathrm{el} \mathrm{Fe}^{+3}$ es liberado debido al $\mathrm{pH}$ ácido $(\mathrm{pH} 5,5$; debido a la bomba de protones dependiente de ATP presente en su membrana, la cual bombea protones desde el citosol al interior del endosoma). Una vez reducido a $\mathrm{Fe}^{+2}$ sale al citosol a través del transportador DMT1 para formar parte del pool de Fe lábil. Por otro lado, la transferrina unida aún a su receptor, regresa a la superficie celular y es liberada a la circulación para su reutilización ${ }^{(16)}$.

\section{REGULACIÓN DEL METABOLISMO DEL HIERRO}

Para mantener la homeostasis de Fe es importante que las proteínas involucradas en la absorción y metabolismo de Fe, tales como DMT1, ferroportina, RTf y ferritina, sean reguladas postranscripcionalmente en una forma dependiente de los niveles intracelulares de Fe. La regulación es mediada por interacciones específicas entre las secuencias IRE (elemento de respuesta a hierro) que se encuentran en los ARNm que codifican para DMT1, ferroportina, ferritina y RTf, entre otras, con las proteínas citoplasmáticas reguladoras de hierro denominadas proteínas reguladoras de hierro (IRPS: IRP1, IRP2) ${ }^{(17)}$.

La unión de las proteínas IRP a los elementos de respuesta a hierro (IRE) aumentan cuando los niveles de Fe intracelular 


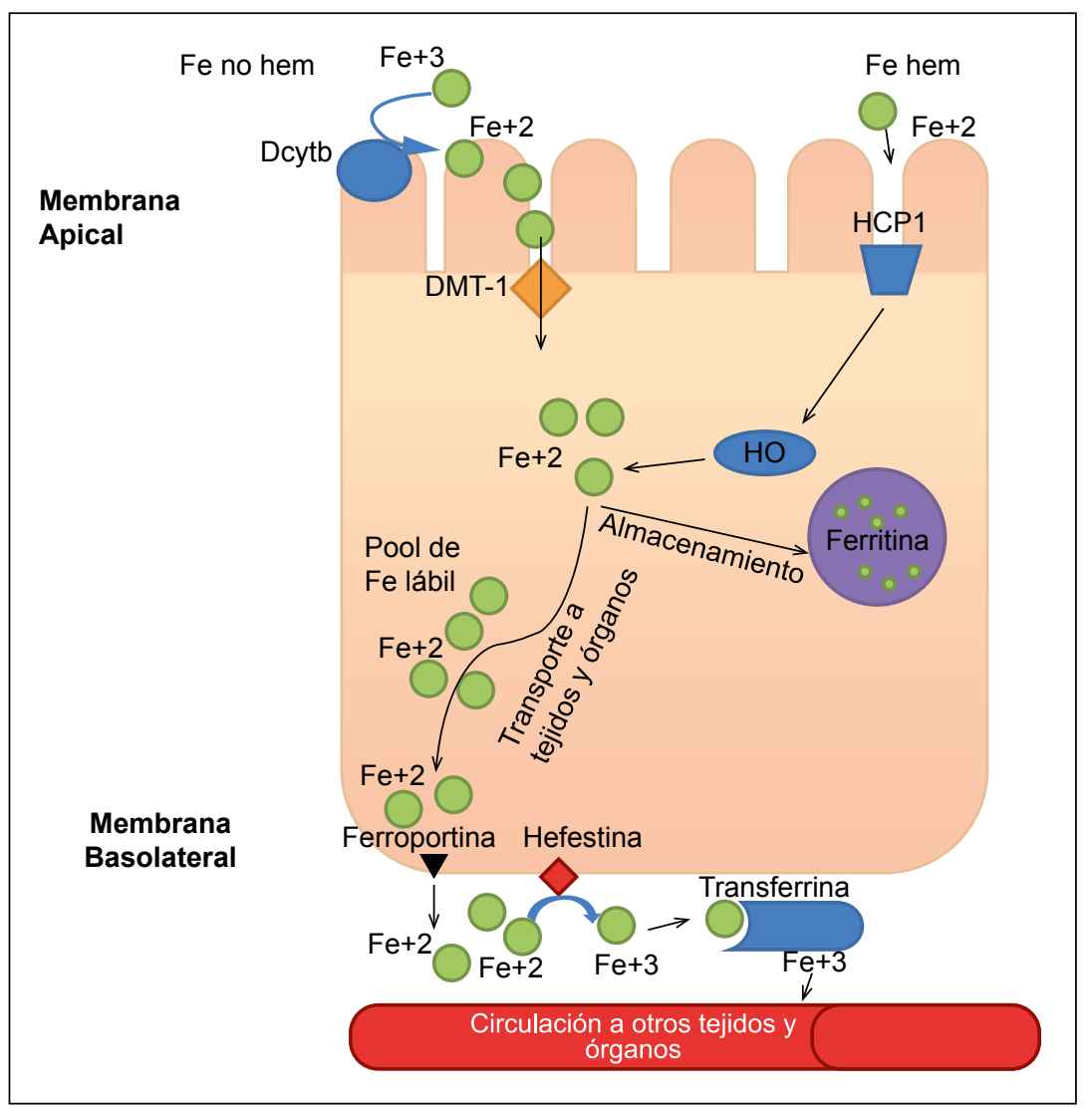

Figura 1. Absorción de hierro hemínico y no hemínico en el enterocito. El hierro no hemínico se reduce a $\mathrm{Fe}^{+2}$ por la DCytB, luego es incorporado al citoplasma por el transportador DMT1, donde forma parte del pool de Fe lábil. El Fe puede ser almacenado en ferritina o ir a la circulación a través de la ferroportina. Luego se oxida a $\mathrm{Fe}^{+3}$ por la hefestina y transportado por la circulación en la transferrina. El Fe hemínico es captado por el transportador HCP1, luego la enzima hem oxigenasa libera al Fe de esta forma sigue igual camino que el Fe no hemínico.

disminuyen. La interacción IRE/IRP estabiliza por ejemplo los ARNm del RTf y DMT1. Por otro lado, esta interacción inhibe la traducción del ARNm que codifica para la ferritina. Esto permite a las células absorber más hierro a través del transportador DMT1 o por RTf -1 y a la vez minimizar su almacenamiento en la ferritina. Por el contrario, cuando hay un aumento del Fe intracelular, IRP1 e IRP2 no se unen a los elementos IRE, lo que permite la degradación de los ARNm de DMT1 y RTf y, a la vez, la traducción del ARNm para la ferritina, favoreciendo así su almacenamiento $y$ evitando la absorción de hierro ${ }^{(18)}$.

\section{HEPCIDINA}

Mención especial requiere la hepcidina $(\mathrm{Hp})$, que corresponde a una hormona peptídica que participa en la regulación sistémica de la homeostasis del $\mathrm{Fe}^{(19)}$. Se sintetiza principalmente en los hepatocitos y en menor grado en el tejido adiposo, corazón, placenta y riñones ${ }^{(20,21)}$. Su función principal es controlar: 1) la llegada del hierro proveniente de los alimentos al plasma a través de los enterocitos; 2 ) de los macrófagos, que contienen el hierro proveniente del reciclaje de los hematíes senescentes y 3 ) el pool de hierro que se libera de los depósitos (hígado, bazo) (22,23).

La producción de $\mathrm{Hp}$ por los hepatocitos está regulada por los niveles de $\mathrm{Fe}$, por lo tanto, cuando el Fe extracelular o de los depósitos está elevado, los hepatocitos producen más Hp, lo que limita la absorción de Fe y la liberación de los depósitos ${ }^{(24)}$. Esto debido a que la $\mathrm{Hp}$, reduce la expresión del transportador apical DMT1 (probablemente también al transportador HCP1), pero, principalmente, induce la internalización y posterior degradación del transportador basolateral ferroportina ${ }^{(25,26)}$. Esto da lugar a una disminución de la exportación del hierro desde los enterocitos, macrófagos y hepatocitos hacia el torrente sanguíneo, disminuyendo así los niveles plasmáticos del metal y aumentando su concentración intracelular en estos tejidos ${ }^{(13)}$. De forma inversa, cuando la expresión de la Hp disminuye, la absorción intestinal, exportación y concentración sérica de hierro aumenta. 


\section{BIOMARCADORES DEL METABOLISMO DE HIERRO}

Los biomarcadores son importantes al momento de predecir la salud y la evolución funcional del metabolismo, y se utilizan de manera rutinaria en la práctica clínica. Por esto, se hace necesario conocer el estado de la nutrición de Fe, por su característica de esencialidad para la vida y por la importancia de este metal en una variedad de trastornos. Entre los biomarcadores del metabolismo de hierro se encuentran: el hematocrito, la hemoglobina, el volumen corpuscular medio, la concentración de hemoglobina corpuscular media, la concentración de hierro sérico, la capacidad total de fijación de hierro y el porcentaje de saturación de la transferrina, la concentración de ferritina sérica y del receptor para transferrina y, finalmente, la hepcidina y la eritroferrona (Figura 2).

Los valores mostrados en la Tabla 1 son solo referenciales. Cada localidad debe contar con sus propios valores de referencia, los cuales dependen del tipo de población: lactante, niños, adultos; de la condición ambiental, ya que algunos de ellos pueden verse afectados por ejemplo con el nivel de altura en el cual vive la población, por lo que cada lugar debe ajustar sus valores a sus respectivas condiciones.

Para el propósito del diagnóstico existen dos etapas claramente definidas que nos dan cuenta del estado inadecuado de la nutrición de hierro: 1) Depleción de los depósitos de hierro: disminución/carencia de depósitos de hierro, pero la concentración de hemoglobina está por sobre del valor determinado para anemia y 2) Anemia ferropriva: los depósitos de hierro están agotados y/o el transporte de hierro es reducido y la concentración de $\mathrm{Hb}$ está por debajo del valor límite. Entonces, se define la anemia ferropénica como la coexistencia de anemia y dos o más de los otros exámenes alterados y deficiencia de hierro sin anemia cuando la concentración de hemoglobina es normal, pero existen dos o más de los otros indicadores alterados y depósitos de hierro disminuidos cuando sólo se encuentra una ferritina sérica bajo el nivel normal.

\section{Hematocrito}

Es la proporción del volumen sanguíneo ocupado por los glóbulos rojos y se ve influenciado por el número y tamaño de la célula. Las concentraciones por debajo del rango de referencia pueden indicar el desarrollo de una anemia (por disminución del número de glóbulos rojos o por una disminución en el tamaño celular, como es el caso de una anemia por deficiencia de hierro (de características microcítica (glóbulo rojo pequeño) e hipocrómico (con una concentración de hemoglobina disminuida) ${ }^{(27)}$.

\section{Hemoglobina $(\mathrm{Hb})$}

La $\mathrm{Hb}$ es el principal componente de los eritrocitos. La síntesis de eritrocitos tiene lugar en la médula ósea y está bajo el control de la eritropoyetina producida por fibroblastos intersticiales en el riñón. El Fe es un componente esencial

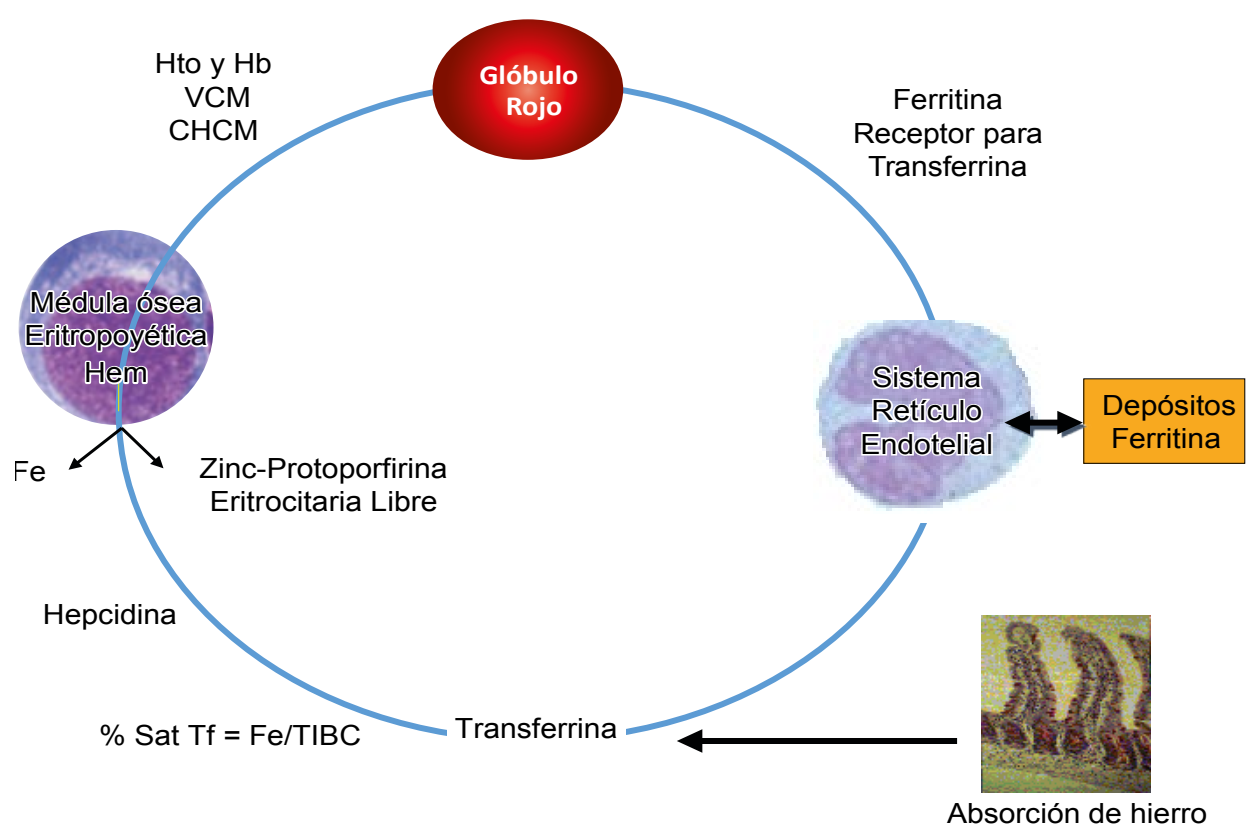

Figura 2. Biomarcadores del metabolismo de hierro. La línea azul denota la circulación sanguínea. Las mediciones se realizan en el glóbulo rojo (VCM; CHCM, ZnPP) y en suero (Fe, TIBC, ferritina, receptor para transferrina, hepcidina). A nivel corporal existen depósitos de hierro en hígado, bazo y sistema retículo endotelial, principalmente. 
del grupo heme que forma parte de la $\mathrm{Hb}$. Una disminución de hierro, induce una disminución en la síntesis del grupo heme y, por lo tanto, una disminución en la síntesis de $\mathrm{Hb}$. Siendo la deficiencia de hierro la causa más común de anemia en el mundo. El contenido de $\mathrm{Hb}$ de los reticulocitos, refleja la disponibilidad de $\mathrm{Fe}$ para la eritropoyesis en médula ósea ${ }^{(27)}$.

Volumen corpuscular medio y concentración de hemoglobina corpuscular media

Ambos parámetros son indicación de la "salud" del glóbulo rojo. El volumen corpuscular medio (VCM) nos habla del tamaño medio del glóbulo rojo. Su valor de referencia oscila entre 82 y 96 fL. Para su cálculo se utiliza la siguiente fórmula:

$$
\mathrm{VCM}=\frac{\text { Hematocrito }(\%) * 10}{\text { Recuento glóbulos rojos }\left(10^{6} / \mu \mathrm{L}\right)}
$$

Niveles bajo este valor (microtosis) pueden estar originados por anemia por deficiencia de hierro talasemias (alteración de la hemoglobina). Valores sobre esta referencia son indicativos de desarrollo de anemias megaloblásticas por deficiencia de vitamina B12 o ácido fólico o trastornos del hígado.

La concentración de hemoglobina corpuscular media ( $\mathrm{CHCM}$ ) es un indicador del contenido de $\mathrm{Hb}$ en un volumen de glóbulos rojos. Sus valores de referencia oscilan entre 32 a $36 \%$. Para su cálculo se utiliza la siguiente fórmula:

$$
\mathrm{CHCM}=\frac{\text { Hemoglobina }(\mathrm{g} / \mathrm{dL}) * 100}{\text { Hematocrito }(\%)}
$$

Valores bajo el nivel de referencia indican anemias de características hipocrómicas (es decir, con poco color, dado por la $\mathrm{Hb}$ ). También se utiliza el concepto de $\mathrm{CHCM}$ elevada o hipercrómica, que se encuentra en enfermedades como la anemia de células falciformes o esferocitosis hereditaria.

\section{Hierro sérico y \% saturación transferrina}

La medición de estos parámetros nos da una indicación de los niveles de hierro circulantes. El Fe sérico en la sangre circula unido a la proteína transferrina (en su estado férrico). A la capacidad de unirse del Fe a esta proteína es lo que se denomina capacidad de la transferrina de unir hierro (TIBC). La medición del contenido de hierro sérico y de la TIBC, permiten evaluar el estado del metabolismo de hierro. Cuando el hierro sérico disminuye, los valores de TIBC aumentan. Con estos dos parámetros se puede calcular, además, el porcentaje de saturación de la transferrina:

$\%$ de saturación de la transferrina $=[\mathrm{Fe}$ sérico $(\mathrm{mg} / \mathrm{dl}) / \mathrm{TIBC}$ $\left.(\mathrm{mg} / \mathrm{dL})]^{*} 100\right)$
Este valor por sí solo es un mejor parámetro para la estimación del estatus de hierro corporal. Su valor oscila entre 20 y $40 \%$. Cuando existe una anemia ferropriva este valor por lo general es menor a $15 \%$.

Ferritina

La ferritina es una proteína de almacenamiento con actividad óxido-reductasa y mineralización de hierro. Se caracteriza por su capacidad de acumular grandes depósitos de hierro no hemínico. La ferritina sérica, además de ser un biomarcador de Fe, también es un marcador de inflamación bien conocido. Se ha considerado un importante indicador de la nutrición de $\mathrm{Fe}$, pero su utilidad es limitada ya que una concentración de ferritina disminuida se asocia con deficiencia de Fe. Sin embargo, al ser una proteína de fase aguda, una inflamación transitoria aumenta sus niveles, pudiendo enmascarar un cuadro.

Existe evidencia de que concentraciones séricas elevadas de ferritina se asocian con mayor riesgo de desarrollo de diabetes y sus complicaciones ${ }^{(28)}$, resistencia a la insulina ${ }^{(29)}$, síndrome metabólico ${ }^{(30)}$ e hipertensión (31). Cuando la exposición a la inflamación es alta, se recomiendan el uso como biomarcadores la concentración de receptor de transferrina soluble (RTfs) (ver abajo) o la relación de RTfs:ferritina ya que serían menos afectados por el proceso inflamatorio ${ }^{(27)}$.

\section{Receptor de transferrina}

A nivel basolateral, el enterocito expresa receptores para transferrina, permitiendo la entrada de Fe transportado por esta proteína. A través de este mecanismo la célula puede detectar el estatus de Fe sistémico, induciendo regulación negativa de su captación vía DMT1 a nivel apical ${ }^{(15)}$. El receptor de transferrina (RTf), que media la captación de Fe celular, cumple un rol clave en la homeostasis del hierro. La mayor proporción del RTf encontrado en el plasma es derivado de los glóbulos rojos y refleja la intensidad de la eritropoyesis y la demanda de hierro. También, la tasa circulante de receptor de la transferrina permite obtener una apreciación cuantitativa de la masa eritroblástica intramedular ${ }^{(32)}$. La concentración del RTf aumenta en la deficiencia de hierro y es un marcador de la severidad de la deficiencia de hierro. La concentración del receptor para transferrina también aumenta en condiciones de anemia hemolítica y talasemias. Estudios clínicos han demostrado que el receptor para transferrina se afecta menos con la inflamación que la ferritina sérica ${ }^{(33)}$.

Hepcidina (Hp)

La desregulación de esta hormona se observa en una variedad de enfermedades relacionadas a $\mathrm{Fe}$, incluyendo hemocromatosis hereditaria, $\beta$-talasemia, anemia de inflamación y anemia ferropénica ${ }^{(34)}$. La regulación de 
Tabla 1. Biomarcadores del metabolismo de hierro

\begin{tabular}{|c|c|c|}
\hline Biomarcador & Definición & Valores* \\
\hline Hematocrito \% (SI) & $\begin{array}{l}\% \text { del volumen de glóbulos rojos, respecto al volu- } \\
\text { men de sangre }\end{array}$ & $\begin{array}{l}\text { Recién Nacido: } 50-65(0,50-0,65) \\
\text { Lactante-niño: } 32-42(0,32-0,42) \\
\text { Hombre adulto: } 42-52(0,42-0,52) \\
\text { Mujer adulta: } 38-45(0,38-0,45)\end{array}$ \\
\hline Hemoglobina g/dL (SI: g/L) & Concentración de hemoglobina circulante & $\begin{array}{l}\text { Recién Nacido: } 15,0-20,0(150-200) \\
\text { Lactante-niño: } 15,0-15,0(110-150) \\
\text { Hombre adulto: } 14,0-17,5(140-175) \\
\text { Mujer adulta: } 12,5-15,0(125-150)\end{array}$ \\
\hline VCM fL $\left(10^{-15} \mathrm{~L}\right)$ & Corresponde al volumen de glóbulos rojos & $\begin{array}{l}\text { Normocíticos: } 82-100 \mathrm{fL} \\
\text { Microcíticos: }<82 \mathrm{fL} \\
\text { Macrocíticos: }>100 \mathrm{fL}\end{array}$ \\
\hline $\mathrm{CHCM}$ g/dL (\%) & Concentración de hemoglobina corpuscular media & $\begin{array}{c}\text { Normocrómicos: } 32-36 \% \\
\text { Hipocrómicos: < } 32 \% \\
\text { Hipercrómicos: > 36\% }\end{array}$ \\
\hline Hierro sérico $\mu \mathrm{g} / \mathrm{dL}(\mu \mathrm{moles} / \mathrm{L})$ & Concentración de hierro sérico circulante & $\begin{array}{l}\text { Rango de Referencia } \\
70-175(12,5-31,5)\end{array}$ \\
\hline TIBC $\mu \mathrm{g} / \mathrm{dL}(\mu \mathrm{moles} / \mathrm{L})$ & Capacidad de fijación total de hierro & $\begin{array}{l}\text { Rango de referencia: } \\
240-450(43,0-80,5)\end{array}$ \\
\hline Saturación Tf (\%) & Saturación de la transferrina medida en porcentaje & $\begin{array}{l}\text { Límite Inferior normal } \\
6 \text { meses a } 6 \text { años: } 9 \\
7 \text { a } 12 \text { años: } 11 \\
\text { Adultos: } 16\end{array}$ \\
\hline Ferritina sérica $(\mu \mathrm{g} / \mathrm{L})$ & Concentración de ferritina sérica circulante & $\begin{array}{c}\text { Depleción de los depósitos: } \\
6 \text { a } 12 \text { meses: } 10 \\
13 \text { a } 24 \text { meses: } 10 \\
2 \text { a } 6 \text { años: } 10 \\
7 \text { a } 12 \text { años: } 10 \\
\text { Adultos: } 12\end{array}$ \\
\hline Receptor para Tf mg/dL & $\begin{array}{l}\text { Concentración del receptor para transferrina soluble } \\
\text { circulante }\end{array}$ & $\begin{array}{l}\text { Rango referencia: } \\
0,8-3,3\end{array}$ \\
\hline Hepcidina $\mu \mathrm{g} / \mathrm{L}$ & Concentración de la hormona hepcidina circulantes & $\begin{array}{l}\text { Rango referencia: } \\
29-254 \text { hombres } \\
17-286 \text { mujeres }\end{array}$ \\
\hline ZnPP ( $\mu$ g/dL glóbulo rojo) & $\begin{array}{l}\text { Concentración de la Zinc-Protoporfirina Eritrocitaria } \\
\text { Libre }\end{array}$ & $\begin{array}{l}\text { Límite superior normal: } \\
6 \text { a } 12 \text { meses: } 120 \\
13 \text { a } 24 \text { meses: } 100 \\
2 \text { a } 6 \text { años: } 80 \\
7 \text { a } 12 \text { años: } 70 \\
\text { Adultos: } 70\end{array}$ \\
\hline
\end{tabular}

* Valores son solo referenciales

la expresión de Hp está controlada por tres demandas principales: 1) El hierro en el suero o en el hígado activan la síntesis de $\mathrm{Hp}$ para prevenir la absorción y mantener la homeostasis; 2) La infección e inflamación activan la síntesis de Hp para que así los microorganismos queden privados del hierro que necesitan para desarrollarse. También se produce un aumento intracelular de hierro en los macrófagos, enterocitos y células hepáticas entre otras. 3) Debido a que la eritropoyesis es la principal demandante de Fe en el organismo, la pérdida de sangre provoca una profunda supresión de la $\mathrm{Hp}$ de los eritrocitos.

\section{Eritroferrona}

Al igual que la $\mathrm{Hp}$, la eritroferrona es una hormona clave en la homeostasis del Fe. Es producida por los eritroblastos en respuesta a la eritropoyetina que suprime la acción de la hepcidina, lo que permite una mayor absorción y movilización del hierro de las reservas después de una hemorragia. Los ratones deficientes en eritroferrona no suprimen la $\mathrm{Hp}$ rápidamente y presentan un retraso en la recuperación de la pérdida de sangre ${ }^{(35)}$.

\section{Zn protoporfirina}

Durante períodos de insuficiencia de $\mathrm{Fe}$ o falla en su utilización, el zinc $(\mathrm{Zn})$ se convierte en un sustrato de metal alternativo para la ferroquelatasa, lo que conduce a una mayor formación de zinc protoporfirina (ZnPP), es decir, un grupo heme que contiene $Z n$ en vez de Fe y por lo tanto no es utilizado para la síntesis de $\mathrm{Hb}$. La evidencia sugiere que esta sustitución del metal es una de las primeras respuestas bioquímicas al agotamiento de $\mathrm{Fe}$, causando el aumento de ZnPP. Debido a que esta sustitución de Zn por Fe ocurre 
principalmente dentro de la médula ósea, la relación ZnPP/ heme en eritrocitos refleja el estado de hierro en la médula ósea. Clínicamente, la cuantificación de ZnPP es valiosa como una herramienta sensible y específica para evaluar la nutrición y el metabolismo del hierro ${ }^{(36)}$. La ZnPP puede detectarse en los hematíes por fluorometría y altos valores de $\mathrm{ZnPP}$, es una medida de la gravedad de la deficiencia de hierro.

\section{HIERRO E INFLAMACIÓN}

Un proceso inflamatorio, aunque sea de características leve puede alterar o enmascarar un cuadro que involucra al metabolismo del hierro. Como se mencionó anteriormente, la ferritina (proteína de almacenaje de hierro), es una proteína de fase aguda, que aumenta durante un proceso inflamatorio o infeccioso sin que exista un cambio en los niveles de hierro sérico, incluso en presencia de anemia, es por ello que el valor de la ferritina debe ser ajustado dependiendo de los niveles de inflamación ${ }^{(37)}$. Es por esto que el centro de control y prevención de enfermedades (CDC) de USA, recomendó medir al menos un parámetro biomarcador de inflamación tales como proteína C-reactiva (PCR) cuando se mida el estatus de hierro corporal ${ }^{(38)}$.

Se ha sugerido que la hepcidina sería uno de los mediadores que participan en el desarrollo de la anemia de la inflamación, la cual es una consecuencia común de las infecciones crónicas y en trastornos inflamatorios generalizados no infecciosos. Estas anemias se caracterizan por una disminución de hierro sérico y de la capacidad de fijación de hierro de la transferrina, aumento de la ferritina y de hierro en los macrófagos de la médula ósea, indicando una disminuida movilización de hierro de depósitos. La inflamación causa hipoferremia a través de un aumento en la producción de hepcidina mediado por citoquinas.

Así, uno de los principales puntos de encuentro entre el metabolismo de hierro y la inflamación es por la hormona hepcidina. La expresión de la hormona hepcidina es estimulada por tres diferentes vías de regulación transcripcional, incluyendo el nivel de hierro sérico. En condiciones de alto hierro, la hepcidina se encuentra aumentada y cuando el hierro baja, la expresión de hepcidina disminuye. Entre las proteínas que regulan aumentando la expresión de la hepcidina están la proteína de la hemocromatosis, la hemojuvelina y el receptor de transferrina 2, quienes regulan la expresión de la hepcidina a través de la vía de las proteínas morfogénicas ósea 6 (BMP6) ${ }^{(39)}$.

Por otro lado, por efecto de las citoquinas proinflamatorias que se generan en respuesta a infecciones por patógenos que son dependientes de hierro, se puede estimular una hipoferremia aguda que inhibe el crecimiento y proliferación de los patógenos. Entre estas citoquinas se puede encontrar a IL-6 II-1, IL-22 e interferón. Este aumento de la regulación de la hepcidina, se produce a través de la señalización de la vía STAT3 en el hígado, que induce finalmente la transcripción de la hepcidina ${ }^{(19,40)}$, aumentando de esta manera el secuestro intracelular del $\mathrm{Fe}$, por lo que hay menor disponibilidad de este mineral para la eritropoyesis, contribuyendo así a lo que se ha denominado como la anemia de la inflamación, también conocida como anemia de enfermedad crónica ${ }^{(41-43)}$. En la anemia de las enfermedades crónicas, la inflamación conduce a la sobreexpresión de la $\mathrm{Hp}$, el bloqueo de la absorción de hierro por los enterocitos y su liberación a partir de macrófagos y hepatocitos ${ }^{(44)}$.

Debe tenerse en cuenta, que en estados que cursan con inflamación crónica media, tal como la obesidad, existe un aumento en la expresión de la citoquina IL-6, en forma independiente a los niveles de hierro circulantes. Esto produce un aumento de la expresión de la hepcidina y, por consiguiente, a una disminución de los niveles circulantes de hierro y un mayor secuestro de hierro en los enterocitos y en los macrófagos. Este cuadro también es parte del llamado anemia de las enfermedades crónicas.

Por otro lado, existen señales que inhiben la secreción de hepcidina provenientes de la eritropoyesis, entre ellas se encuentra proteínas como la eritroferrona, el factor de diferenciación del crecimiento 15 (GDF15) y el factor modulador de señalización BMP de gastrulación retorcido (TWSG1) que inhibe la vía SMAD7 (una de las vías de activación de la secreción de hepcidina). También tiene un efecto inhibidor de la secreción de la hepcidina la proteína matriptasa-2, la cual bloquea a la hemojuvelina e impide la activación del complejo BMP-10 ${ }^{(45)}$. Otras señales que inhiben la síntesis de hepcidina son la hipoxia tisular y los factores estimulantes de la eritropoyesis (tal como la eritropoyetina. El aumento de la eritropoyesis se acompaña de una supresión de la hepcidina. Esto podría representar una nueva estrategia para el tratamiento de la anemia de las enfermedades crónicas. Por otro lado, los inhibidores como la prolil-hidroxilasa, inducen hipoxia y aumentan la síntesis de eritropoyetina, disminuyendo así la secreción de hepcidina, trayendo como consecuencia un aumento de la hemoglobina en los individuos ${ }^{(45)}$.

\section{PUNTOS QUE DESTACAR}

El hierro es un elemento esencial para el organismo.

El hierro en condiciones de exceso es tóxico y por su actividad redox produce daño a estructuras tales como ADN, proteínas y lípidos a través de especies reactivas al oxígeno.

La absorción de hierro es dependiente de los depósitos del metal y su absorción se realiza por un mecanismo altamente regulado por la célula.

Existen múltiples biomarcadores del metabolismo del hierro utilizados para conocer su estatus en el organismo. 
La anemia por deficiencia de hierro es la carencia nutricional más prevalente en el mundo.

Procesos infecciosos y/o inflamatorios pueden desencadenar el cuadro denominado anemia de las enfermedades crónicas.
Fuentes de financiamiento: autofinanciado.

Contribuciones de autoría: CGS, MJA y MA participaron en la concepción del artículo, redacción del artículo, revisión crítica y aprobación de la versión final.

\section{REFERENCIAS BIBLIOGRÁFICAS}

1. Aisen P, Enns C, Wessling-Resnick M. Chemistry and biology of eukaryotic iron metabolism. Int J Biochem Cell Biol. 2001;33(10):940-959.

2. Pantopoulos K, Porwal SK, Tartakoff A, Devireddy L. Mechanisms of mammalian iron homeostasis. Biochemistry (Mosc). 2012;51(29):5705-5724.

3. McCord JM. Iron, free radicals, and oxidative injury. En: Seminars in hematology. 1998. p. 5-12.

4. Pietrangelo A. The ferroportin disease. Blood Cells Mol Dis. 2004;32(1):131138.

5. Conrad ME, Umbreit JN. Pathways of iron absorption. Blood Cells Mol Dis. 2002;29(3):336-355.

6. Hentze MW, Muckenthaler MU, Andrews NC. Balancing acts: molecular control of mammalian iron metabolism. Cell. 2004;117(3):285-297.

7. Miret S, Simpson RJ, McKie AT. Physiology and molecular biology of dietary iron absorption. Annu Rev Nutr. 2003;23(1):283-301.

8. Derman DP, Bothwell TH, Torrance JD, Macphail AP, Bezwoda WR, Charlton $\mathrm{RW}$, et al. Iron absorption from ferritin and ferric hydroxide. Eur J Haematol. 1982;29(1):18-24.

9. Anderson GJ, Frazer DM, McKie AT, Vulpe CD, Smith A. Mechanisms of haem and non-haem iron absorption: lessons from inherited disorders of iron metabolism. Biometals. 2005;18(4):339348.

10. Sharp P, Srai SK. Molecular mechanisms involved in intestinal iron absorption. World J Gastroenterol WJG. 2007;13(35):4716.

11. De Domenico I, Ward DM, Kaplan J. Regulation of iron acquisition and storage: consequences for iron-linked disorders. Nat Rev Mol Cell Biol. 2008;9(1):72-81.

12. Yip R. Hierro. En: Bowman B, Rusell R. Conocimientos actuales en nutrición. En Washington D.C.: Organización Mundial de la Salud; p. 340-59.
13. Fleming RE, Bacon BR. Orchestration of iron homeostasis. N Engl J Med. 2005;352(17):1741-1744.

14. Shayeghi M, Latunde-Dada GO, Oakhill JS, Laftah AH, Takeuchi K, Halliday N, et al. Identification of an intestinal heme transporter. Cell. 2005;122(5):789-801.

15. Conrad ME, Umbreit JN. Iron absorption and transport-an update. Am J Hematol. 2000;64(4):287-298.

16. Chung J, Wessling-Resnick M. Molecular mechanisms and regulation of iron transport. Crit Rev Clin Lab Sci. 2003;40(2):151-182.

17. Klausner RD, Rouault TA, Harford JB. Regulating the fate of mRNA: the control of cellular iron metabolism. Cell. 1993;72(1):19-28.

18. Johansson HE, Theil EC. Ironresponse element (IRE) structure and combinatorial RNA regulation. Mol Cell Iron Transp N Y Marcel Dekker Inc. 2002;237-53.

19. Nemeth E, Tuttle MS, Powelson J, Vaughn MB, Donovan A, Ward DM, et al. Hepcidin regulates cellular iron efflux by binding to ferroportin and inducing its internalization. Science. 2004;306(5704):2090-2093.

20. Valore EV, Ganz T. Posttranslational processing of hepcidin in human hepatocytes is mediated by the prohormone convertase furin. Blood Cells Mol Dis. 2008;40(1):132-138.

21. Collins JF, Wessling-Resnick M, Knutson MD. Hepcidin regulation of iron transport. J Nutr. 2008;138(11):2284-2288.

22. Ramey G, Deschemin J-C, Durel B, Canonne-Hergaux F, Nicolas G, Vaulont $S$. Hepcidin targets ferroportin for degradation in hepatocytes. Haematologica. 2010;95(3):501-504.

23. Conde DS, de Las Cuevas AR, Conde GE. Current status of iron metabolism: Clinical and therapeutic implications. Med Clin (Barc). 2017;148(5):218-224.

24. Ramos E, Kautz L, Rodriguez R, Hansen M, Gabayan V, Ginzburg Y, et al. Evidence for distinct pathways of hepcidin regulation by acute and chronic iron loading in mice. Hepatology. 2011;53(4):1333-1341.

25. Mena NP, Esparza A, Tapia V, Valdés P, Nunez MT. Hepcidin inhibits apical iron uptake in intestinal cells. Am J Physiol-Gastrointest Liver Physiol. 2008;294(1):G192-G198.

26. Morgan EH, Oates PS. Mechanisms and regulation of intestinal iron absorption. Blood Cells Mol Dis. 2002;29(3):384399.

27. Northrop-Clewes CA, Thurnham DI. Biomarkers for the differentiation of anemia and their clinical usefulness. J Blood Med. 2013;4:11.

28. Jung CH, Lee MJ, Hwang JY, Jang JE, Leem J, Park J-Y, et al. Elevated serum ferritin level is associated with the incident type 2 diabetes in healthy Korean men: a 4 year longitudinal study. PLoS One. 2013;8(9):e75250.

29. Pham NM, Nanri A, Yi S, Kurotani K, Akter S, Foo LH, et al. Serum ferritin is associated with markers of insulin resistance in Japanese men but not in women. Metabolism. 2013;62(4):561-567.

30. Li J, Wang R, Luo D, Li S, Xiao C. Association between serum ferritin levels and risk of the metabolic syndrome in Chinese adults: a population study. PloS One. 2013;8(9):e74168.

31. Kim MK, Baek KH, Song K-H, Kang MI, Choi JH, Bae JC, et al. Increased serum ferritin predicts the development of hypertension among middle-aged men. Am J Hypertens. 2012;25(4):492-497.

32. Gammella E, Buratti P, Cairo G, Recalcati $S$. The transferrin receptor: the cellular iron gate. Metallomics. 2017

33. Beguin Y. Soluble transferrin receptor for the evaluation of erythropoiesis and iron status. Clin Chim Acta. 2003;329(1):9-22.

34. Evstatiev R, Gasche C. Iron sensing and signalling. Gut. 2011;gut-2010.

35. Kautz L, Jung G, Valore EV, Rivella $S$, Nemeth E, Ganz T. Identification of 
erythroferrone as an erythroid regulator of iron metabolism. Nat Genet. 2014;46(7):678-684.

36. Labbé RF, Vreman HJ, Stevenson DK. Zinc protoporphyrin: a metabolite with a mission. Clin Chem. 1999;45(12):2060-2072.

37. Brito A, Hertrampf E, Olivares M. Iron status biomarkers and C-reactive protein in children aged 19 to 72 months in Chile. Food Nutr Bull. 2013;34(1):14-20.

38. Centers for Disease Control and Prevention. Recommendations to prevent and control iron deficiency in the United States. MMWR Morb Mortal Wkly Rep.1998;47:1-29.
39. Daher R, Karim Z. Iron metabolism: State of the art. Transfus Clin Biol. 2017;24(3):115-119.

40. Schmidt PJ. Regulation of iron metabolism by hepcidin under conditions of inflammation. J Biol Chem. 2015;290(31):18975-18983.

41. Pietrangelo A, Dierssen U, Valli L, Garuti C, Rump A, Corradini E, et al. STAT3 is required for IL-6-gp130-dependent activation of hepcidin in vivo. Gastroenterology. 2007;132(1):294-300.

42. Falzacappa MVV, Spasic MV, Kessler R, Stolte J, Hentze MW, Muckenthaler MU. STAT3 mediates hepatic hepcidin expression and its inflammatory stimulation. Blood. 2007;109(1):353-358.
43. Wrighting DM, Andrews NC. Interleukin-6 induces hepcidin expression through STAT3. Blood. 2006;108(9):3204-3209.

44. Weiss G, Goodnough LT. Anemia of chronic disease. N Engl J Med. 2005;352(10):1011-1023.

45. Conde S, de Las Cuevas R, Conde E. Current status of iron metabolism: Clinical and therapeutic implications. Med Clin (Barc). 2017;148(5):218-224.

Correspondencia: Miguel Arredondo.

Dirección: Laboratorio de Micronutrientes,

INTA, Universidad de Chile. El Líbano 5524, Macul, Santiago, Chile.

Teléfono: 56-2-29781483.

Correoelectrónico:marredon@inta.uchile.cl

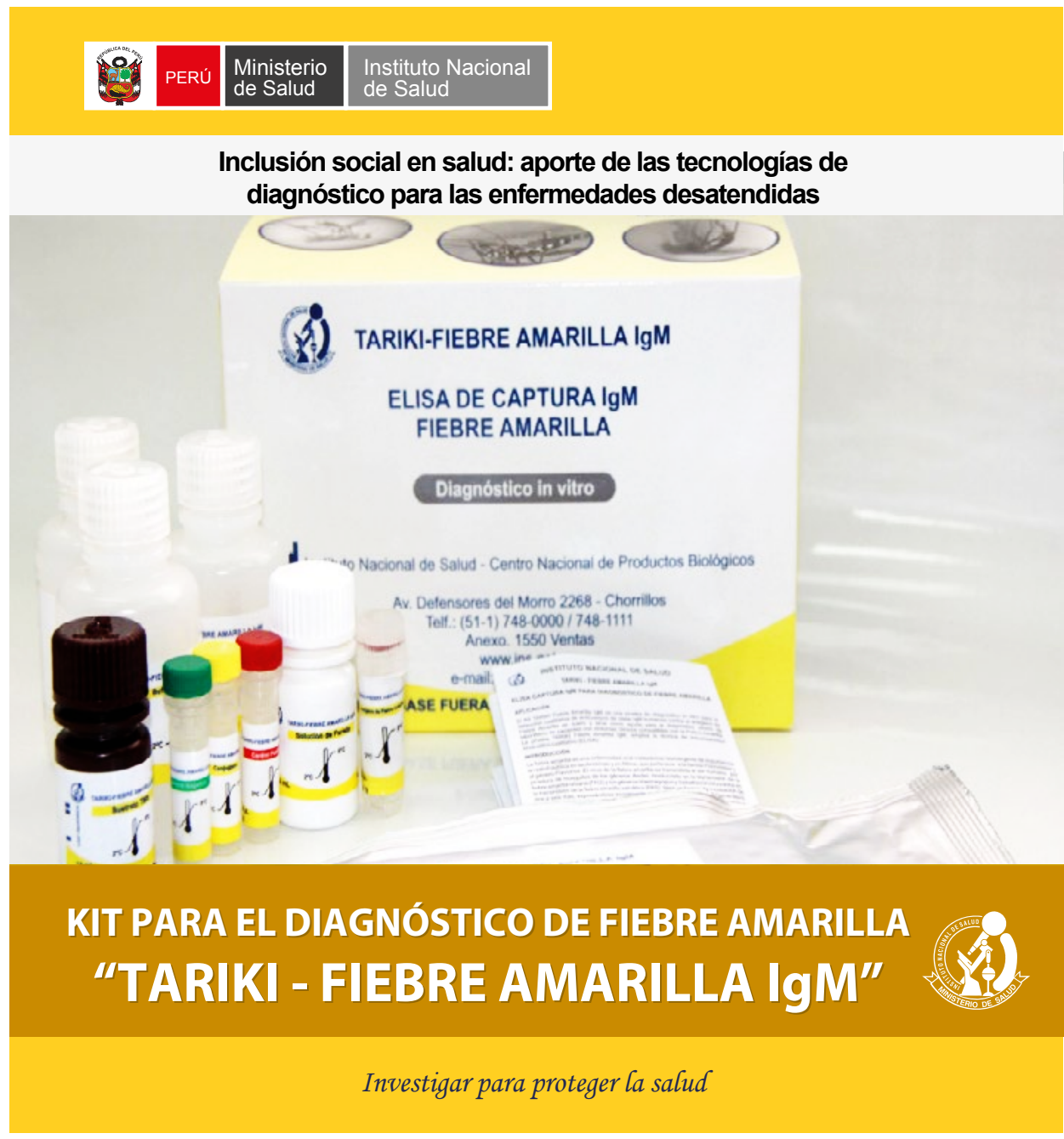

